\title{
Update on thyroid eye disease and management
}

This article was published in the following Dove Press journal:

Clinical Ophthalmology

14 October 2009

Number of times this article has been viewed

\author{
Erick D Bothun ${ }^{1,2}$ \\ Ryan A Scheurer' \\ Andrew R Harrison ${ }^{1,3}$ \\ Michael S Lee ${ }^{1,4,5}$ \\ 'Departments of Ophthalmology, \\ ${ }^{2}$ Pediatrics, ${ }^{3}$ Otolaryngology, \\ ${ }^{4}$ Neurosurgery, and ${ }^{5}$ Neurology, \\ University of Minnesota, Minneapolis, \\ Minnesota, USA
}

\begin{abstract}
Thyroid eye disease is a heterogeneous autoimmune orbital reaction typically manifesting in middle age. The inflammation may parallel or remain isolated from a related inflammatory cascade in the thyroid called Graves' disease. The orbital manifestations can lead to severe proptosis, dry eyes, strabismus, and optic neuropathy. In this article, we will discuss this unique condition including the ophthalmic findings and management.
\end{abstract}

Keywords: Graves' disease, thyroid eye disease, proptosis, orbital decompression, enlarged extraocular muscles

\section{Pathogenesis and epidemiology}

The overwhelming majority $(90 \%)$ of thyroid eye disease (TED) cases are associated with hyperthyroidism, while the rest are either euthyroid or hypothyroid. ${ }^{1}$ Crossreactivity against shared antigen(s) in thyroid and orbital tissue is most likely responsible for the autoimmune ophthalmologic reaction. Antibodies involving the thyroid-stimulating hormone (TSH) receptor may drive the pathogenesis of this inflammation. ${ }^{2}$ Autoreactive $T$ lymphocytes migrate into the orbital soft tissue, fat and musculature reacting with the shared thyroid and orbital antigen(s). The inflammation results in anatomical changes including eyelid retraction (NOSPECS class I) and redness and swelling of periorbital tissues (class II) including the eyelids, conjunctiva, and caruncle. ${ }^{3,4}$ Secretion of a cytokine cascade stimulates fibroblast proliferation and secretion of glycosaminoglycans resulting in proptosis (class III) from retro-orbital fat expansion and extraocular muscle swelling. The expansion of orbital tissues may lead to the severe motility disorders (class IV), corneal exposure (class V) and optic nerve damage (class VI). Eventually this process results in fibrosis of the extraocular musculature and permanent restriction of eye and lid movements.

Both endogenous (genetic factors, increased age, male sex) and exogenous factors (smoking, thyroid dysfunction, and radioiodine treatment) likely contribute to the development or severity of TED. ${ }^{5,6}$ Approximately half of Graves' disease patients experience ophthalmic manifestations, with sight-threatening disease in $3 \%$ to $5 \%$ of cases. ${ }^{7}$ The heterogeneous manifestations and variable course of TED may greatly affect the quality of life in affected patients.

Although TED is a heterogeneous genetic disorder, finding a common genetic loci remains elusive. Candidate genes include human leukocyte antigen (HLA, 6p21-3), cytotoxic T-lymphocyte antigen-4 (CTLA-4, 2q33), tumor necrosis factor (TNF, 6p21-3), interferon- $\gamma, 12 q 14)$, intercellular adhesion molecule-1 (ICAM-1, 19p13), and thyroid 
stimulating hormone receptor gene (TSH-R, 14q13). ${ }^{5}$ TED exhibits a female to male ratio of $4: 1$; however, more severe disease occurs among affected elderly males. ${ }^{8}$

\section{Course of disease}

Thyroid eye disease typically has an inflammatory, active phase subsiding over one to two years (range 6 months to 5 years) into a fibrotic, inactive phase (Figure 1). ${ }^{9}$ After the inflammation subsides, patients may suffer permanent structural changes around the eyes requiring treatment. Active inflammation recurs in about $1 \%$ of patients after months to years of inactivity. Unfortunately, no reliable test or sign exists to determine when the inactive phase has begun. These patients return for repeat evaluations to document changes in symptoms or clinical findings. Stable clinical findings for 6 months suggest that the patient has passed from the active to the inactive phase. It is important to recognize every patient's course ofTED is different and unique. Some may have minimal signs while others have sudden onset of severe complications such as severe diplopia, proptosis and vision loss.

Smoking has a strong relationship with the course and severity of thyroid eye disease. The relationship is doseresponsive between cigarette use and probability of developing thyroid eye disease. ${ }^{10}$ Smoking is associated with an increased risk of ophthalmic disease after radioiodine therapy and worse or delayed outcomes for treatment of thyroid eye disease. ${ }^{11}$

\section{Clinical findings}

Ophthalmic findings are generally bilateral, but may present unilaterally or asymmetrically. ${ }^{1}$ The presence of pre-existing

\section{Course of thyroid eye disease}

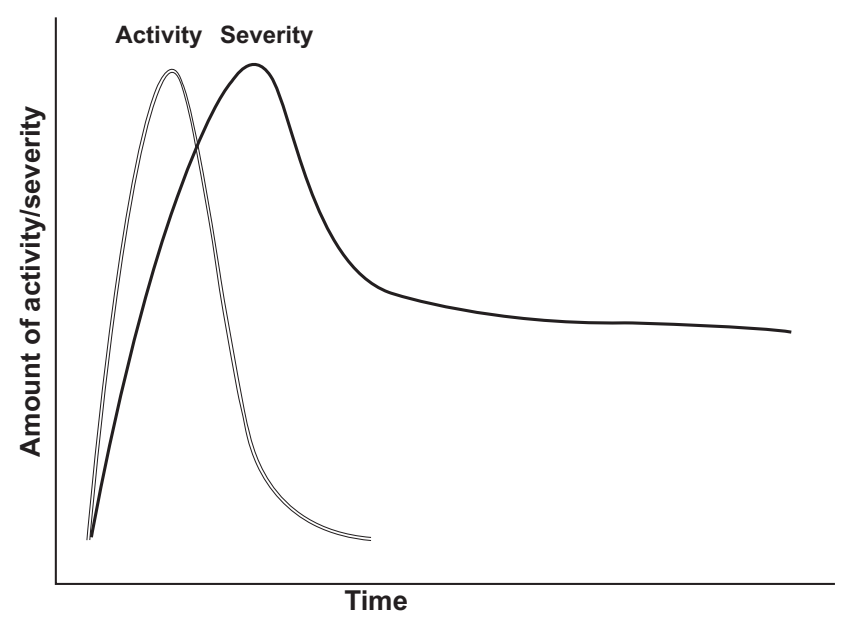

Figure I Rundle's curve mapping increase in disease activity or severity followed by a reduction over time. autoimmune thyroid disease increases suspicion for TED, but isolated eye findings may represent the presenting manifestations of thyroid disorders. The classic presentation in the setting of acute Graves' disease involves thyrotoxicosis, goiter and bilateral exophthalmos. In one cohort of 120 TED patients, clinical features included: eyelid retraction $91 \%$, exophthalmos $62 \%$, extraocular muscle dysfunction $43 \%$, ocular pain $30 \%$, lacrimation $23 \%$, and optic nerve disease $6 \%{ }^{12}$

The earliest findings in TED usually involve mild soft tissue inflammation. Early symptoms include foreign body sensation, excessive tearing from dry eye, conjunctival or eyelid redness and swelling, blurred vision, and retro-orbital pain. Dilated conjunctival vasculature, keratoconjunctivitis, and corneal staining may be seen on slit lamp examination.

As the orbital inflammation progresses in severity, swelling of the extraocular muscles (EOM) or orbital soft tissue often manifests as chemosis, lid edema and ocular proptosis..$^{13}$ The EOM may become visible as blood vessels over their anterior portion show prominence. Such vessel engorgement overlying the lateral rectus has been described as a sign of activity; ${ }^{14}$ however this may persist during the inactive disease phase. ${ }^{13}$ Poor venous drainage secondary to the congestive mass effect behind the eyes may contribute to redness and swelling of the eyelids, conjunctiva, and caruncle. Involvement of the levator palpebrae results in eyelid retraction and the characteristic "stare" of TED (Figure 2). This appearance is often exaggerated by the presence of exophthalmos. Progressive proptosis with eyelid retraction and meibomian gland inflammation may worsen corneal exposure and progress to corneal ulceration and perforation. ${ }^{15,16}$ Inflammation and scarring of the EOM can cause strabismus and ophthalmoplegia. In mild cases, patients might feel a pulling sensation around the eyes. With more advanced disease, horizontal, vertical and torsional strabismus and double vision ensues (Figure 3). Asymmetric EOM restriction manifests as incomitant deviations with diplopia in eccentric gazes, ie, sidegaze esotropia or upgaze hypotropia with medial or inferior involvement respectively. In severe cases the restrictive, incomitant strabismus occurs in primary gaze and patients complain of constant double vision. In addition to vertical and torsional tropias, inferior rectus involvement may lead to a poor Bell's phenomenon with increased risk of corneal exposure. Diffuse orbital and EOM restriction may lead to intermittent spiking or chronic elevation of intraocular pressure. Intraocular pressures should regularly be tested in both primary and upgaze. Strabismus may develop at any stage in the disease or secondary to orbital changes after decompression surgery. In addition, 


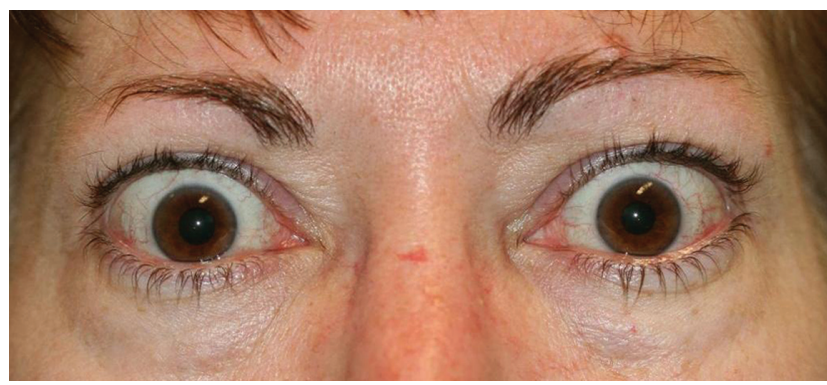

Figure 2 Severe inflammation and proptosis with classic "stare" of thyroid eye disease may be prominent in the active phase of disease.

vertical rectus strabismus surgery may cause iatrogenic eyelid retraction and worsen corneal exposure.

With severe inflammation, the expansion of soft tissues confined within the bony orbit and swelling of the muscles at the apex of the orbit may compress the optic nerve causing dysthyroid optic neuropathy (Figure 4). ${ }^{17}$ Although early symptoms include progressive blurring of vision and fading of colors in one or both eyes, visual acuity may be preserved in a minority of patients with optic neuropathy. ${ }^{18}$ Of note, when optic neuropathy occurs the degree of proptosis often does not correlate. Presumably, this occurs when the enlarged EOM expand to compress the optic nerve instead of producing exophthalmos. Signs of optic neuropathy include decrease in visual acuity, visual field, and color vision along with the development of an afferent pupillary defect. Bilateral, simultaneous optic neuropathy can occur which would eliminate a relative afferent pupillary defect. The optic disc may be normal or edematous. Without detection through serial screenings and subsequent prompt treatment, permanent optic atrophy and visual loss may occur.

Careful evaluation of TED patients presenting to an ophthalmologist allows for quantitative assessment disease activity and severity. ${ }^{17}$ Activity of thyroid eye disease can be assessed with the Clinical Activity Score (Table 2). ${ }^{19}$ The clinical features of inflammation are graded based upon comparison with photographs to improve objectivity. ${ }^{17}$ Severity may be assessed using the NOSPECS classification; this mnemonic for evaluation assists in differentiation of mild, moderate, and severe disease (Table 1). ${ }^{3,20}$ Impairment of quality of life can be elicited with the Graves'-ophthalmopathy specific QOL questionnaire (GO-QoL) ${ }^{21}$ Initial laboratory studies include bloodwork for thyroid stimulating hormone (TSH), thyroid stimulating immunoglobulin (TSIG), thyroid peroxidase (TPO) antibody, and TSH receptor antibody.

Lastly, radiographic imaging using CT, MRI, or ultrasound may aid in the diagnosis of thyroid eye disease.

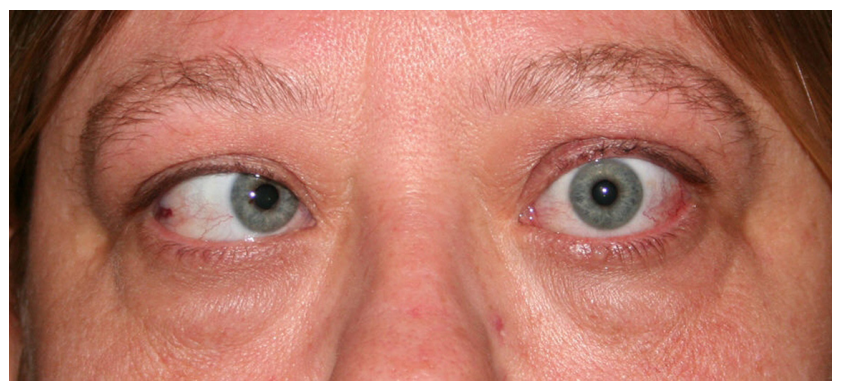

Figure 3 Esotropia strabismus is a common manifestation of medial rectus enlargement in thyroid eye disease.

CT scanning is the modality of choice to evaluate dysthyroid optic neuropathy and the planning of surgical intervention. Findings often include enlargement of orbital fat or musculature with sparing of insertions. The inferior and medial recti are most commonly affected. Other finding on imaging include intracranial prolapse of fat through the superior orbital fissure, straightening of the optic nerve or impingement of apical musculature on the optic nerve.

The differential diagnosis for the clinical features of thyroid eye disease includes infectious and inflamamatory orbital conditions such as orbital myositis, idiopathic orbital inflammatory syndrome, and orbital cellulitis. Rarer conditions include orbital neoplasms and carotid artery cavernous sinus fistulas. New onset diplopia may result from cranial nerve palsies, internuclear ophthalmoplegia, or myasthenia gravis.

\section{Management}

Patients with Graves' ophthalmopathy should be managed by a coordinated team of primary care physicians,

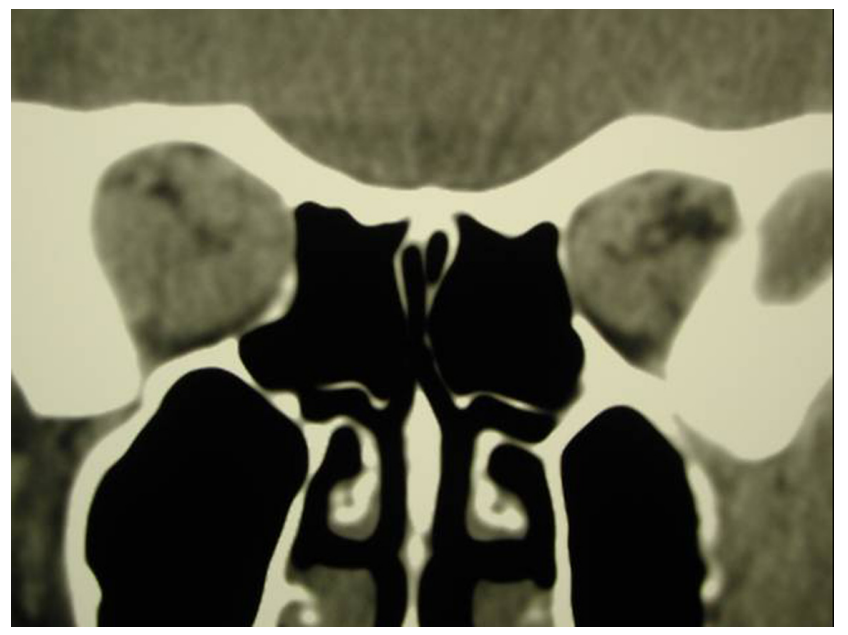

Figure 4 CT imaging of extraocular muscle enlargement at orbital apex. 
Table I Clinical activity or severity may be assessed with either the Clinical Activity Score (CAS) or the NOSPECS severity assessment

\section{Clinical Activity Score (CAS)}

Score determined by sum of the symptoms

and signs in a patient with TED at a given visit

Spontaneous retrobulbar pain

Pain on attempted up-gaze or down-gaze

Redness of the eyelids

Redness of the conjunctiva

Swelling of the eyelids

Inflammation of the caruncle and/or plica

Edema of the conjunctiva

\section{NOSPECS Severity Assessment}

Class 0

Class I

Class 2

Class 3

Class 4

Class 5

Class 6
No signs or symptoms

Only signs, no symptoms

Soft tissue involvement

Proptosis

Extraocular muscle involvement

Corneal involvement

Sight loss
Lid aperture (mm)

Swelling, redness

Exophthalmos (mm)

Ductions (degrees), diplopia score (0, no diplopia; I, intermittent: diplopia in primary position of gaze when tired or awake; 2 , inconstant: diplopia at extremes of gaze; 3 , constant: diplopia always present)

Punctate keratopathy, ulceration

Optic nerve involvement: changes in visual acuity, color vision, visual fields, or optic disk endocrinologists, and ophthalmologists with specialty experience in managing TED. This typically involves a neuro-ophthalmologist, an orbital surgeon, and a strabismus surgeon. The complicated nature of treatment often requires coordination of medical, surgical and radiation therapy. ${ }^{22}$ Uncontrolled thyroid function is associated with more severe thyroid eye disease..$^{23,24}$ However, antithyroid drugs and surgical subtotal/near-total thyroidectomy therapies typically do not improve the ophthalmic disease course. ${ }^{25,26}$ In fact, radioiodine therapy for Graves' disease can exacerbate ophthalmic disease; particularly in the context of smoking, active disease, or elevated TSH-receptor autoantibodies. ${ }^{27,28}$ Administration of steroids during and following radioiodine therapy decreases the risk of exacerbation in patients with active TED. ${ }^{29}$ When radioiodine is administered to patients with inactive TED, risk of eye disease exacerbation is minimal. ${ }^{30}$

Ophthalmologic treatment must be tailored to the patient's quality of life,psycho-social effects, and severity and stage of disease. Smoking cessation is mandatory in all phases because it worsens outcome and represents a modifiable risk factor. ${ }^{31}$ Mild, early disease does not require surgical or immunomodulating therapy and clinicians may choose to wait and monitor signs. Management can be symptomatic with lubricating eye drops and ointments for corneal exposure and temporary prisms for diplopia. ${ }^{32}$ Serial examinations are necessary to screen for progression of disease and determination of stability. Moderately severe or severe worsening of orbital congestion and/or severe proptosis can occur with concurrent dysthyroid disease or many years after well-controlled thyroid function from Graves' disease. When sight is threatened from optic neuropathy or corneal breakdown, urgent referral is necessary to initiate "rescue" therapy, often with glucocorticoid administration and/or orbital decompression. Once the chronic inflammation associated with TED becomes quiescent and a period of stability is noted, "rehabilitative" surgical therapies may be considered.

\section{Rescue therapy}

When moderate to severe TED is present, early "rescue" intervention may be indicated. Indications for "rescue" include evidence of optic neuropathy, signficant proptosis and extensive exposure keratopathy. Urgent "rescue" treatment, either alone or a combination, includes corticosteroids, surgical orbital decompression, and orbital radiation.

Severe thyroid eye disease is often treated initially with glucocorticoids. The efficacy and tolerability of intravenous administration (IV) is superior to oral or local injection. Oral glucocorticoids, typically prednisone 60 to $100 \mathrm{mg} /$ day, must be taken over an extended period of time. ${ }^{33,34}$ With oral glucocorticoids, bisphosphonates should be considered 
Table 2 Proposed methyprednisolone dosing regimens

\begin{tabular}{ll}
\hline Author & Proposed methylprednisolone dosing regimen \\
\hline Kahaly $^{40}$ & $\begin{array}{l}\text { iv methylprednisolone once weekly; } 0.5 \mathrm{~g} \text {, then } 0.25 \mathrm{~g}, \\
6 \text { wk each ( } 4.5 \mathrm{~g} \text { total) }\end{array}$ \\
van Geest ${ }^{41}$ & $\begin{array}{l}\text { iv methylprednisolone } 500 \mathrm{mg} \text {, over } 3 \text { consecutive days, in } \\
4 \text { cycles at } 4 \text { weekly intervals }(6 \mathrm{~g} \text { total) }\end{array}$ \\
Marcocci $^{42}$ & $\begin{array}{l}\text { iv methylprednisolone; } 15 \mathrm{mg} / \mathrm{kg} \text { for } 4 \text { cycles and then } 7.5 \\
\mathrm{mg} / \mathrm{kg} \text { for } 4 \text { cycles; each cycle consisted of } 2 \text { infusions on } \\
\text { alternate days at } 2 \text {-week intervals }(9 \text { to } 12 \mathrm{~g} \text { total) }\end{array}$ \\
\hline
\end{tabular}

for limitation of osteoporosis..$^{35}$ Intravenous glucocorticoids pulse therapy may be more effective and better tolerated than oral glucocorticoids.$^{36}$ Marcocci et al found optic neuropathy improved in 11 of 14 patients receiving IV steroids vs 3 of 9 taking glucocorticoids orally. Additionally, the final Clinical Activity Score convalesced IV as compared to the oral glucocorticoid treated group. Improvement in symptoms generally occurs after 1 to 2 weeks of high dose intravenous glucocorticoids. ${ }^{37}$ Rarely adverse effects have included reports of acute liver damage and failure at high doses. ${ }^{38}$ For this reason, it is recommended to confine the cumulative glucocorticoid dose to less than $8 \mathrm{~g}^{39}$ (Table 2). . $^{36,40,41}$

Alternatively, some surgeons feel intraorbital injection of glucocorticoids provide relief of ophthalmologic symptoms with minimal systemic side effects. ${ }^{34}$ A dose of $20 \mathrm{mg}$ triamcinolone (Kenalog ${ }^{\circledR} 40 \mathrm{mg} / \mathrm{mL}$ ) monthly is injected into the inferior lateral quadrant of the orbit. There is disagreement, ${ }^{42}$ however, between data comparing injections to other forms of steroid administration..$^{43}$

Orbital decompression has been a mainstay in historical treatment for TED. Medical therapies have come to replace surgical for the initial management of certain cases of dysthyroid optic neuropathy although both are efficacious. ${ }^{44}$ When contraindications exist to medical management or disease is refractory to trial of glucocorticoids and radiation, urgent surgical decompression is necessary. Decompression for optic neuropathy traditionally involves removal of the medial and inferior walls. ${ }^{45}$ Access to these structures is achieved through transconjunctival or transcaruncular incisions. Otolaryngology may also decompress the posterior medial orbit through a transphenoidal approach. Removal of sufficient posterior bone is important for decompressing optic neuropathy.

The use of botulinum toxin for dysmotility in TED was first described by Scott. ${ }^{46}$ Early in the disease course, a botulinum extraocular muscle injection may temporarily improve motility. However as the disease progresses and the musculature becomes more fibrotic, lasting effects are often limited. Botulinum administration to the levator complex has been shown to temporarily improve lid retraction and corneal exposure. ${ }^{47}$

The data surrounding use of external ionizing orbital radiation is mixed. Clinical application of such therapy for dysthyroid optic neuropathy lacks conclusive support. Orbital radiation in the active disease phase showed no efficacy in one report. ${ }^{48}$ Radiation is equally as effective as oral glucocorticoids ${ }^{49}$ yet the combination of treatments provide better results than either individual therapy. ${ }^{50}$ In trials approximately $60 \%$ of patients respond to radiation. ${ }^{51} \mathrm{~A}$ recent report reviewing orbital radiation found improvement in extraocular motility; however, no evidence of improvement in proptosis, eyelid retraction, or soft tissue swelling. ${ }^{52}$ Lower doses of radiation, 1 Gy per week for 20 weeks, have been shown to be equally effective and better tolerated than higher doses, 20 Gy per orbit over 2 weeks. ${ }^{53,54}$ Safety of orbital radiation is encouraging; new onset of definite radiation retinopathy is $1 \%$ to $2 \%$ over 10 years. ${ }^{55}$ Absolute contraindications include diabetic retinopathy and severe hypertension, while young age represents a relative contraindication. ${ }^{56}$ Fortunately, radiation therapy does not appear to compromise future surgical therapies. ${ }^{57}$

Rehabilitative surgical therapy, as described below, is best initiated after six months of stable, inactive thyroid eye disease.$^{58}$ If decompression surgery is performed in the active phase, additional decompression may be necessary due to inflammatory changes that persist post-operatively. Additionally, spontaneous remission of symptoms is possible with resolution of the active phase. Wise timing could, therefore, spare patients from unnecessary procedures.

\section{Rehabilitative surgical therapy}

Rehabilitative surgical therapies are implemented for stable, inactive TED. Such surgical therapy typically involves orbital decompression, strabismus surgery, eyelid repositioning and blepharoplasty. Patients with mild disease may only require one of these restorative procedures. Conversely, patients with severe disease may require all three types of surgery in succession as needed. The order of these procedures is important because decompression may alter or create strabismus, and strabismus surgery on vertical recti can alter eyelid positioning.

\section{Orbital decompression surgery}

Traditional indications for decompression involved predominantly optic neuropathy and severe exposure keratopathy. Currently medical therapy including external beam radiotherapy may be considered prior to decompression 

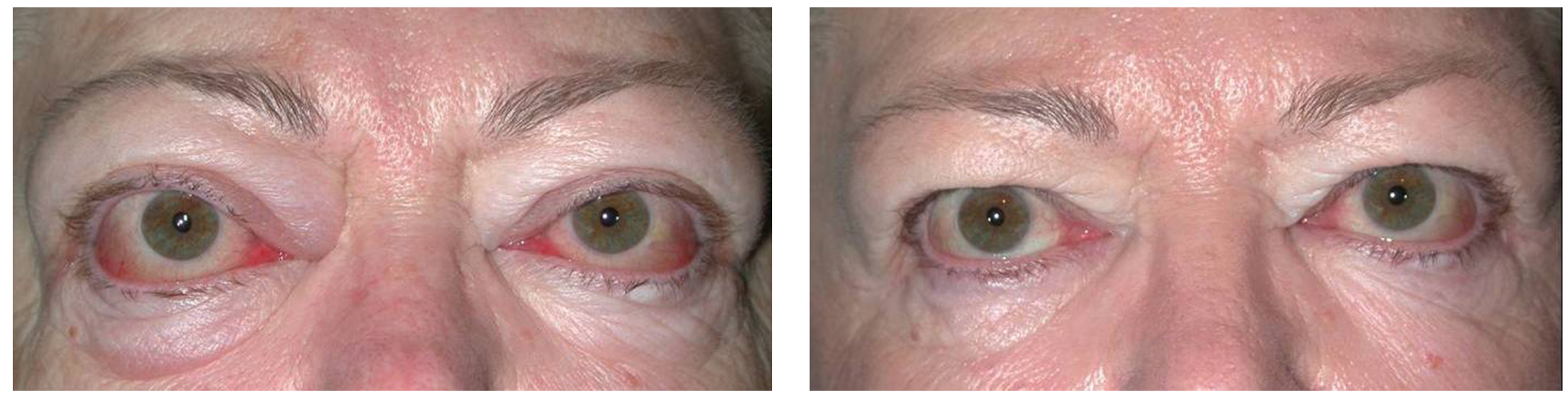

Figures 5 (left) and 6 (right) Pre- and post-operative orbital decompression images document a marked decrease in proptosis.

for optic neuropathy. Proptosis has expanded as a surgical indication to include decompression for cosmesis; and decompression is often utilized to provide relief of congestion. Orbital decompression involves either removal of or thinning of any combination of orbital wall surfaces in addition to removal of orbital fat. In bony decompression, additional space is created for soft tissues to prolapse, often into the ethmoid or maxillary sinuses, temporal fossa, and/or cranial cavity. Removal of the inferior wall with the medial, inferomedial and lateral, balanced medial and lateral, and deep lateral wall decompression are common techniques. Alteration of the orbital vault structure can lead to new onset of diplopia.

In patients lacking diplopia before surgery a medial and lateral balanced decompression has been advocated. The objective of this technique is to decrease morbidity including hypoglobus and imbalanced motility. Endoscopic medial and external lateral technique has been shown to provide effective orbital decompression and compares favorably to 3-wall decompression. ${ }^{59}$

Deep lateral wall decompression has reportedly reduced proptosis as much as $6 \mathrm{~mm}$. (Figures 5,6) Lateral wall decompression alone has a low rate of new onset diplopia of approximately $7 \%$, with reports as low as $2.6 \% .{ }^{39}$ Complications of deep lateral decompression include

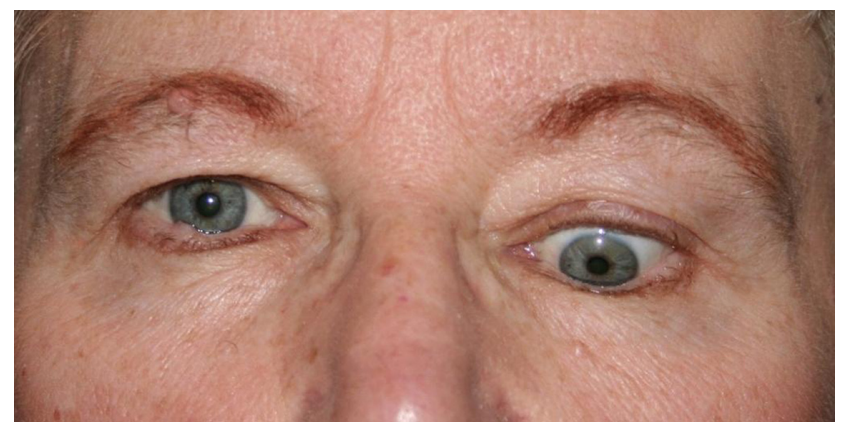

cerebrospinal fluid leaks. A volume expansion of $5.6 \mathrm{cc}$ may be achieved with this procedure alone. ${ }^{60}$ Deep lateral decompression may also be combined with removal of other walls as needed.

\section{Fat decompression}

Removal of intraconal fat reduces congestive orbitopathy, proptosis, and may improve preoperative diplopia. Selection of patients is important and CT or MRI is useful in assessing those with predominantly fatty or muscular soft tissue enlargement. ${ }^{61}$ Patients with orbital fat expansion experience better outcomes from fat-only decompression than patients with predominantly extraocular muscle enlargement. Decompression typically involves the inferolateral and superomedial compartments with removal of 3-6 cc of intraconal fat. Safety has been verified with proper selection of patients with orbital fat volume expansion, and new onset diplopia is rare. ${ }^{6}$ Intraconal fat debulking may be utilized alone or in combination with bony decompression.

\section{Strabismus}

Thyroid eye disease patients often develop diplopia and strabismus requiring surgical correction. The restrictions in motility are most commonly hypotropia or esotropia caused

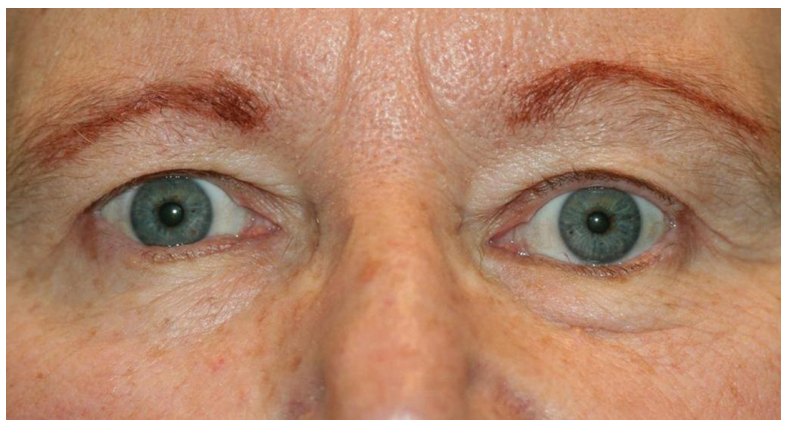

Figures 7 (left) and 8 (right) Pre- and post-operative strabismus surgery images document improvement of motor alignment. 

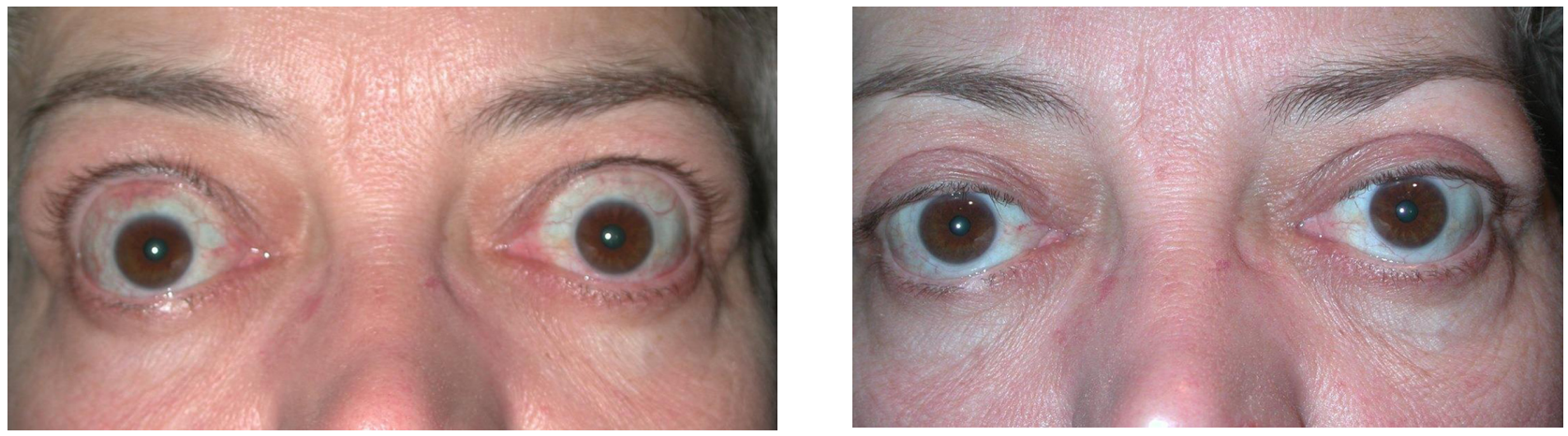

Figures 9 (left) and 10 (right) Pre- and post-operative eyelid retraction repair images document improvement of eyelid position.

by inferior and medial rectus involvement respectively. Strabismus may present with the onset of orbitopathy or as a direct result of decompression surgery. Patients with preoperative diplopia undergoing inferior and medial wall decompression may experience worsening. ${ }^{63}$ Surgical correction of strabismus is, therefore, planned after decompression. The primary goal of strabismus surgery in TED is restoration of single binocular vision in primary gaze and reading position. (Figures 7,8) Managing patient expectations is important and the surgeon should counsel that single binocular vision in all fields may not be possible. Resection of extraocular muscles is rarely recommended due to the fibrosis and restriction of musculature. Muscle recession on adjustable sutures are frequently utilized since results are more unpredictable compared to the pediatric population. ${ }^{64} \mathrm{~A}$ single surgery functions sufficiently in $85 \%$ of cases with reoperation or prism use in the remainder. ${ }^{65}$ Approximately $25 \%$ of all TED patients use prisms or adopt an abnormal head positioning after surgery.

\section{Eyelid repositioning and blepharoplasty}

Surgery for lengthening eyelids and reducing retraction is frequently performed for patients. Benefits include improvement in symptoms of corneal exposure and appearance. Eyelid repositioning should take place after orbital decompression and strabismus surgeries since vertical rectus surgery may alter eyelid position. ${ }^{66}$ (Figures 9, 10) Patients with TED often develop significant fatty prolapse and dermatochalasis of the eyelids requiring blepharoplasty. This procedure may be performed in concert with eyelid repositioning, but often is performed later as a separate procedure.

\section{Future therapies}

Controversial therapies include a variety of other immunomodulatory agents. Cyclosporine has been shown to work synergistically when used with glucocorticoids. ${ }^{67}$ Other research suggests that agents including rituximab and etanercept may be beneficial. ${ }^{68,69}$ Agents with less proven value include azathioprine, ciamexone, iv immunoglobulin, and somatostatin analogs. There is hope for future use of therapies targeting the immune system and the pathophysiologic mechanism of thyroid eye disease, however, no conclusive data yet exists.

\section{Summary}

Patients with thyroid eye disease necessitate serial examinations and at times intensive specialty care for the ocular manifestations of this disfiguring and potentially blinding disorder. At the University of Minnesota such care is orchestrated by the Center for Thyroid Eye Disease where patients are cared for at each clinical visit by a neuro-ophthalmologist, orbital and oculoplastic surgeon, and strabismologist. Through this multispecialty approach, the patient's strategic management and outcome are maximized.

\section{Acknowledgments}

Supported, in part, by an unrestricted Departmental grant from Research to Prevent Blindness, Inc., New York, NY, USA.

\section{Disclosures}

The authors disclose no conflicts of interest.

\section{References}

1. Burch HB, Wartofsky L. Graves' ophthalmopathy: current concepts regarding pathogenesis and management. Endocr Rev. 1993;14(6):747-793.

2. Bahn RS, Dutton CM, Natt N, et al. Thyrotropin receptor expression in Graves' orbital adipose/connective tissues: potential autoantigen in Graves' ophthalmopathy. J Clin Endocrinol Metab. 1998;83(3):998-1002.

3. Werner SC. Classification of the eye changes of Grave's disease. J Clin Endocrinol Metab. 1969;29(7):982-984.

4. Yamada M, Li AW, Wall JR. Thyroid-associated ophthalmopathy: clinical features, pathogenesis, and management. Crit Rev Clin Lab Sci. 2000;37(6):523-549. 
5. Bednarczuk T, Gopinath B, Ploski R, Wall JR. Susceptibility genes in Graves' ophthalmopathy: searching for a needle in a haystack? Clin Endocrinol (Oxf). 2007;67(1):3-19.

6. Manji N, Carr-Smith JD, Boelaert K, et al. Influences of age, gender, smoking, and family history on autoimmune thyroid disease phenotype. J Clin Endocrinol Metab. 2006;91(12):4873-4880.

7. Bartalena L, Pinchera A, Marcocci C. Management of Graves' ophthalmopathy: reality and perspectives. Endocr Rev. 2000;21(2): 168-199.

8. Perros P, Crombie AL, Matthews JN, Kendall-Taylor P. Age and gender influence the severity of thyroid-associated ophthalmopathy: a study of 101 patients attending a combined thyroid-eye clinic. Clin Endocrinol (Oxf). 1993;38(4):367-372.

9. Rundle FF, Wilson CW. Development and course of exophthalmos and ophthalmoplegia in Graves' disease with special reference to the effect of thyroidectomy. Clin Sci. 1945;5:177-194.

10. Pfeilschifter J, Ziegler R. Smoking and endocrine ophthalmopathy: impact of smoking severity and current vs lifetime cigarette consumption. Clin Endocrinol (Oxf). 1996;45(4):477-481.

11. Eckstein A, Quadbeck B, Mueller G, et al. Impact of smoking on the response to treatment of thyroid associated ophthalmopathy. $\mathrm{Br} J$ Ophthalmol. 2003;87(6):773-776.

12. Bartley GB, Fatourechi V, Kadrmas EF, et al. Clinical features of Graves' ophthalmopathy in an incidence cohort. Am J Ophthalmol. 1996;121(3):284-290.

13. Mourits MP, Koornneef L, Wiersinga WM, Prummel MF, Berghout A, van der Gaag R. Clinical criteria for the assessment of disease activity in Graves' ophthalmopathy: a novel approach. Br J Ophthalmol. 1989;73(8):639-644.

14. Sergott RC, Felberg NT, Savino PJ, Blizzard JJ, Schatz NJ. Graves' ophthalmopathy - immunologic parameters related to corticosteroid therapy. Invest Ophthalmol Vis Sci. 1981;20:173-182.

15. Gilbard JP, Farris RL. Ocular surface drying and tear film osmolarity in thyroid eye disease. Acta Ophthalmol (Copenh). 1983:61(1):108-116.

16. Dickinson AJ, Perros P. Controversies in the clinical evaluation of active thyroid-associated orbitopathy: use of a detailed protocol with comparative photographs for objective assessment. Clin Endocrinol (Oxf). 2001;55(3):283-303.

17. Wiersinga WM, Perros P, Kahaly GJ, et al. Clinical assessment of patients with Graves' orbitopathy: the European Group on Graves' Orbitopathy recommendations to generalists, specialists and clinical researchers. Eur J Endocrinol. 2006;155(3):387-389.

18. McKeag D, Lane C, Lazarus JH, et al. Clinical features of dysthyroid optic neuropathy: a European Group on Graves' Orbitopathy (EUGOGO) survey. Br J Ophthalmol. 2007;91(4):455-458.

19. Mourits MP, Prummel MF, Wiersinga WM, Koornneef L. Clinical activity score as a guide in the management of patients with Graves' ophthalmopathy. Clin Endocrinol (Oxf). 1997;47(1):9-14.

20. Bartley GB. Evolution of classification systems for Graves' ophthalmopathy. Ophthal Plast Reconstr Surg. 1995;11(4):229-237.

21. Terwee CB, Gerding MN, Dekker FW, Prummel MF, Wiersinga WM. Development of a disease specific quality of life questionnaire for patients with Graves' ophthalmopathy: the GO-QOL. Br J Ophthalmol. 1998;82(7):773-779.

22. Wiersinga WM. Combined thyroid-eye clinics. In: Wiersinga WM, Kahaly GJ, editors. Graves' Orbitopathy: A Multidisciplinary Approach. Basel: Karger; 2007:96-99.

23. Prummel MF, Wiersinga WM, Mourits MP, Koornneef L, Berghout A, van der Gaag R. Amelioration of eye changes of Graves' ophthalmopathy by achieving euthyroidism. Acta Endocrinol (Copenh). 1989;121 Suppl 2:S185-S190.

24. Prummel MF, Wiersinga WM, Mourits MP, Koornneef L, Berghout A, van der Gaag R. Effect of abnormal thyroid function on the severity of Graves' ophthalmopathy. Arch Intern Med. 1990;150(5):1098-1101.

25. Bartalena L, Marcocci C, Bogazzi F, et al. Relation between therapy for hyperthyroidism and the course of Graves' ophthalmopathy. $N$ Engl J Med. 1998;338(2):73-78.
26. Menconi F, Marinò M, Pinchera A, et al. Effects of total thyroid ablation versus near-total thyroidectomy alone on mild to moderate Graves' orbitopathy treated with intravenous glucocorticoids. J Clin Endocrinol Metab. 2007;92(5):1653-1658.

27. Tallstedt L, Lundell G, Tørring O, et al. Occurrence of ophthalmopathy after treatment for Graves' hyperthyroidism. The Thyroid Study Group. N Engl J Med. 1992;326(26):1733-1738.

28. Bartalena L, Marcocci C, Bogazzi F, et al. Relation between therapy for hyperthyroidism and the course of Graves' ophthalmopathy. NEngl J Med. 1998;338(2):73-78.

29. Bartalena L, Marcocci C, Bogazzi F, Panicucci M, Lepri A, Pinchera A. Use of corticosteroids to prevent progression of Graves' ophthalmopathy after radioiodine therapy for hyperthyroidism. $N \mathrm{Engl}$ J Med. 1989;321(20):1349-1352.

30. Perros P, Kendall-Taylor P, Neoh C, Frewin S, Dickinson J. A prospective study of the effects of radioiodine therapy for hyperthyroidism in patients with minimally active graves' ophthalmopathy. $J$ Clin Endocrinol Metab. 2005;90(9):5321-5323.

31. O'Hare JA, Georghegan M. Cigarette smoking as a promoter of Graves' disease. Eur J Intern Med. 1993;4:289-292.

32. Uddin JM, Davies PD. Treatment of upper eyelid retraction associated with thyroid eye disease with subconjunctival botulinum toxin injection. Ophthalmology. 2002;109(6):1183-1187.

33. Bartalena L, Marcocci C, Pinchera A. Treating severe Graves' ophthalmopathy. Baillieres Clin Endocrinol Metab. 1997;11(3): 521-526.

34. Ebner R, Devoto MH, Weil D, et al. Treatment of thyroid associated ophthalmopathy with periocular injections of triamcinolone. $\mathrm{Br} J$ Ophthalmol. 2004;88(11):1380-1386.

35. Bartalena L, Pinchera A, Marcocci C. Management of Graves' ophthalmopathy: reality and perspectives. Endocr Rev. 2000;21(2):168-199.

36. Marcocci C, Bartalena L, Tanda ML, et al. Comparison of the effectiveness and tolerability of intravenous or oral glucocorticoids associated with orbital radiotherapy in the management of severe Graves' ophthalmopathy: results of a prospective, single-blind, randomized study. J Clin Endocrinol Metab. 2001;86(8):3562-3567.

37. Hart RH, Kendall-Taylor P, Crombie A, Perros P. Early response to intravenous glucocorticoids for severe thyroid-associated ophthalmopathy predicts treatment outcome. J Ocul Pharmacol Ther. 2005;21(4):328-336.

38. Marinó M, Morabito E, Brunetto MR, Bartalena L, Pinchera A, Marocci C. Acute and severe liver damage associated with intravenous glucocorticoid pulse therapy in patients with Graves' ophthalmopathy. Thyroid. 2004;14(5):403-406.

39. Ben Simon GJ, Wang L, McCann JD, Goldberg RA. Primary-gaze diplopia in patients with thyroid-related orbitopathy undergoing deep lateral orbital decompression with intraconal fat debulking: a retrospective analysis of treatment outcome. Thyroid. 2004;14(5):379-383.

40. Kahaly GJ, Pitz S, Hommel G, Dittmar M. Randomized, single blind trial of intravenous versus oral steroid monotherapy in Graves' orbitopathy. J Clin Endocrinol Metab. 2005;90(9):5234-5240.

41. Van Geest RJ, Sasim IV, Koppeschaar HP, et al. Methylprednisolone pulse therapy for patients with moderately severe Graves' orbitopathy: a prospective, randomized, placebo-controlled study. Eur J Endocrinol. 2008;158(2):229-237.

42. Marcocci C, Bartalena L, Panicucci M, et al. Orbital cobalt irradiation combined with retrobulbar or systemic corticosteroids for Graves' ophthalmopathy: a comparative study. Clin Endocrinol (Oxf). 1987;27(1):33-42.

43. Goldberg RA. Editorial: Orbital steroid injections. Br J Ophthalmol. 2004;88(11):1359-1360.

44. Wakelkamp IM, Baldeschi L, Saeed P, Mourits MP, Prummel MF, Wiersinga WM. Surgical or medical decompression as a first-line treatment of optic neuropathy in Graves' ophthalmopathy? A randomized controlled trial. Clin Endocrinol (Oxf). 2005;63(3):323-328. 
45. Mourits MP, Koornneef L, Wiersinga WM, Prummel MF, Berghout A, van der Gaag R. Orbital decompression for Graves' ophthalmopathy by inferomedial, by inferomedial plus lateral, and by coronal approach. Ophthalmology. 1990;97(5):636-641.

46. Scott AB. Injection treatment of endocrine orbital myopathy. Doc Ophthalmol. 1984;58(1):141-145.

47. Uddin JM, Davies PD. Treatment of upper eyelid retraction associated with thyroid eye disease with subconjunctival botulinum toxin injection. Ophthalmology. 2002;109(6):1183-1187.

48. Gorman CA, Garrity JA, Fatourechi V, et al. A prospective, randomized, double-blind, placebo-controlled study of orbital radiotherapy for Graves' ophthalmopathy. Ophthalmology. 2001;108(9):1523-1534.

49. Prummel MF, Mourits MP, Blank L, Berghout A, Koornneef L, Wiersinga WM. Randomized double-blind trial of prednisone versus radiotherapy in Graves' ophthalmopathy. Lancet. 1993;342(8877):949-954.

50. Marcocci C, Bartalena L, Bogazzi F, Bruno-Bossio G, Lepri A, Pinchera A. Orbital radiotherapy combined with high dose systemic glucocorticoids for Graves' ophthalmopathy is more effective than radiotherapy alone: results of a prospective randomized study. J Endocrinol Invest. 1991;14(10):853-860.

51. Mourits MP, van Kempen-Harteveld ML, García MB, Koppeschaar HP, Tick L, Terwee CB. Radiotherapy for Graves’ orbitopathy: randomised placebo-controlled study. Lancet. 2000;355(9214):1505-1509.

52. Bradley EA, Gower EW, Bradley DJ, et al. Orbital radiation for graves ophthalmopathy: a report by the American Academy of Ophthalmology. Ophthalmology. 2008;115(2):398-409.

53. Kahaly GJ, Rösler HP, Pitz S, Hommel G. Low- versus high-dose radiotherapy for Graves' ophthalmopathy: a randomized, single blind trial. J Clin Endocrinol Metab. 2000;85(1):102-108.

54. Nakahara H, Noguchi S, Murakami N, et al. Graves ophthalmopathy: MR evaluation of 10-Gy versus 24-Gy irradiation combined with systemic corticosteroids. Radiology. 1995;196(3):857-862.

55. Wakelkamp IM, Tan H, Saeed P, et al. Orbital irradiation for Graves' ophthalmopathy: Is it safe? A long-term follow-up study. Ophthalmology. 2004;111(8):1557-1562.

56. Marquez SD, Lum BL, McDougall IR, et al. Long-term results of irradiation for patients with progressive Graves' ophthalmopathy. Int J Radiat Oncol Biol Phys. 2001;51(3):766-774.

57. Baldeschi L, MacAndie K, Koetsier E, Blank LE, Wiersinga WM. The influence of previous orbital irradiation on the outcome of rehabilitative decompression surgery in graves orbitopathy. Am J Ophthalmol. 2008;145(3):534-540.
58. Bartalena L, Baldeschi L, Dickinson AJ, et al. Consensus statement of the European group on Graves' orbitopathy (EUGOGO) on management of Graves` orbitopathy. Thyroid. 2008;18(3):333-346.

59. Silver RD, Harrison AR, Goding GS. Combined endoscopic medial and external lateral orbital decompression for progressive thyroid eye disease. Otolaryngol Head Neck Surg. 2006;134(2):260-266.

60. Goldberg RA, Kim AJ, Kerivan KM. The lacrimal keyhole, orbital door jamb, and basin of the inferior orbital fissure. Three areas of deep bone in the lateral orbit. Arch Ophthalmol. 1998;116(12):1618-1624.

61. Forbes G, Gorman CA, Brennan MD, Gehring DG, Ilstrup DM, Earnest F 4th. Ophthalmopathy of Graves' disease: computerized volume measurements of the orbital fat and muscle. AJNR Am J Neuroradiol. 1986;7(4):651-656.

62. Trokel S, Kazim M, Moore S. Orbital fat removal. Decompression for Graves orbitopathy. Ophthalmology. 1993;100(5):674-682.

63. Nunery WR, Nunery CW, Martin RT, Truong TV, Osborn DR. The risk of diplopia following orbital floor and medial wall decompression in subtypes of ophthalmic Graves' disease. Ophthal Plast Reconstr Surg. 1997;13(3):153-160.

64. Shorr N, Seiff SR. The four stages of surgical rehabilitation of the patient with dysthyroid ophthalmopathy. Ophthalmology. 1986;93(4) 476-483.

65. Lueder GT, Scott WE, Kutschke PJ, Keech RV. Long-term results of adjustable suture surgery for strabismus secondary to thyroid ophthalmopathy. Ophthalmology. 1992;99(6):993-997.

66. Bartalena L, Pinchera A, Marcocci C. Management of Graves' ophthalmopathy: reality and perspectives. Endocr Rev. 2000;21(2): 168-199.

67. Prummel MF, Mourits MP, Berghout A, et al. Prednisone and cyclosporine in the treatment of severe Graves' ophthalmopathy. $N$ Engl J Med. 1989;321(20):1353-1359.

68. El Fassi D, Nielsen CH, Hasselbalch HC, Hegedüs L. Treatmentresistant severe, active Graves' ophthalmopathy successfully treated with B lymphocyte depletion. Thyroid. 2006;16(7):709-710.

69. Paridaens D, van den Bosch WA, van der Loos TL, Krenning EP, van Hagen PM. The effect of etanercept on Graves' ophthalmopathy: a pilot study. Eye. 2005;19(12):1286-1289.
Clinical Ophthalmology

\section{Publish your work in this journal}

Clinical Ophthalmology is an international, peer-reviewed journal covering all subspecialties within ophthalmology. Key topics include: Optometry; Visual science; Pharmacology and drug therapy in eye diseases; Basic Sciences; Primary and Secondary eye care; Patient Safety and Quality of Care Improvements. This journal is indexed on

\section{Dovepress}

PubMed Central and CAS, and is the official journal of The Society of Clinical Ophthalmology (SCO). The manuscript management system is completely online and includes a very quick and fair peer-review system, which is all easy to use. Visit http://www.dovepress.com/ testimonials.php to read real quotes from published authors. 